\title{
The use of simulation when designing road junctions
}

\author{
Vyacheslav Terentyev ${ }^{1}$, Konstantin Andreev ${ }^{1, *}$, Nikolay Anikin ${ }^{1}$, Natalya Morozova ${ }^{2}$, \\ Alexander Shemyakin ${ }^{1}$ \\ ${ }^{1}$ FSBEI HE RSATU, 1, Kostychev Str., Ryazan, Russia \\ ${ }^{2}$ Ryazan Institute (branch) of Moscow Polytechnic University, 53, Lenin Str., Ryazan, Russia
}

\begin{abstract}
The high level of motorization in most countries of the world is the reason for the increase in the number of car accidents. Currently, it is understood that a further increase in the number of cars without significant changes in the transport infrastructure will only aggravate the already difficult situation on roads. The article addresses the issues of road traffic injuries and statistical information on road accidents. The analysis of the work of leading transport engineers presents the results of studies on the use of computer modeling tools for designing road conditions at various levels. From the presented analysis, it is possible to conclude that the most suitable tool for assessing the safety of road junctions is the PTV VISSIM software package, which also allows to export vehicle trajectories to SSAM software. In the framework of the analytic survey of the intersection safety, based on the analysis of vehicle trajectories, the parameters of the future conflict of the planned road junctions were established. Studies have shown that a road junction at different levels makes possible to triple the safety of junctions in comparison with the roundabout. The use of simulation allows not to wait for emergency cases, but to evaluate hypothetical structures and alternative layout options for road junctions, where it is not possible to use traditional, statistical models for assessing the probability of car accidents.
\end{abstract}

\section{Introduction}

Road transport is an important economic tool significantly effecting the pace of socioeconomic growth of the society as a whole. The level of motorization in the world has shown steady growth over a long period of time. Road transport is the dominant mode of transport in several countries. The high growth rate of the fleet of cars, in addition to economic reasons, is also due to the high level of comfort in the operation of automobiles, which allows for the transportation of passengers and goods in the optimal time and on the shortest route. A well-developed road network of good quality is also a priority, influencing the choice of the method of transporting goods or passengers [1,2].

At the moment, it is obvious that the intensive growth of the fleet of motor vehicles in most countries of the world has led to a number of negative consequences. The increased

\footnotetext{
*Corresponding author: kosta066@yandex.ru
} 
traffic of cars is the main reason for the decrease in the speed of movement on roads, which is caused by the mismatch of their traffic capacity with a sharp increase in the number of vehicles. A prominent increase of the ratio of vehicles to population has led to a decrease in the operation efficiency of street and road networks [3]. For the same reason, difficulties in the movement of cars on roads with controlled traffic are often noted, which negatively affects the environmental situation. It should be noted that reducing road safety (an increase in the number of emergencies and the number of conflict points) is an urgent problem when a high level of motorization [4].

According to a summary of the United Nations and the World Health Organization, deaths from car accidents (1.2 million victims annually) are confidently holding a leading position among the causes of death. Therefore, at present, many countries have set themselves a task of lowering this indicator. The main goal of "Vision Zero" is that the number of fatal accidents should be reduced to zero in the long run. In January 2018, the Government of the Russian Federation approved the Road Safety Strategy in the Russian Federation for 2018-2024, which stated that one of the main directions of its implementation is to improve the street-road network in terms of road safety, including the development of road traffic management [5].

According to the State Inspectorate for Road Safety of the Russian Federation for 20162018, 511,225 car accidents occurred on Russian roads. This is about 3-4 times higher than in Europe. For three years, 57,610 people died and 651,367 people were injured as a result of car accidents (Table 1) [6]. According to the NHTSA's National Center for Statistics and Analysis in the United States for the same period, these figures were 18,340 dead and more than 220 thousand people were injured. As we see road traffic injuries in the United States as well as in Europe are much lower than in Russia.

Table 1. Car accident rates in the Russian Federation for 2016-2018.

\begin{tabular}{|c|c|c|c|c|c|c|}
\hline Year & $\begin{array}{c}\text { Number of } \\
\text { car accidents }\end{array}$ & $\begin{array}{c}\text { Indicator } \\
\text { change, \% }\end{array}$ & $\begin{array}{c}\text { Killed, } \\
\text { persons }\end{array}$ & $\begin{array}{c}\text { Indicator } \\
\text { change, \% }\end{array}$ & $\begin{array}{c}\text { Injured, } \\
\text { persons }\end{array}$ & $\begin{array}{c}\text { Indicator } \\
\text { change, \% }\end{array}$ \\
\hline 2016 & 173,694 & -5.6 & 20308 & -12.1 & 221,140 & -4.3 \\
\hline 2017 & 169,432 & -2.5 & 19088 & -6.1 & 215,374 & -2.7 \\
\hline 2018 & 168,099 & -0.8 & 18214 & -4.6 & 214,853 & -0.3 \\
\hline
\end{tabular}

An analysis of circumstances of car accidents allows to conclude that in the vast majority of cases, the causes of emergency situations are incorrect actions of drivers when assessing the road situation and the "behavior" of the car at the time of the accident. Currently, there are no tools for assessing road safety indicators or the degree of risk when driving a vehicle in a conflict situation. Accurate determining the level of accidents in a certain section of the road network requires processing of statistical data for a sufficiently long period of time. A special analysis of statistical information on traffic conditions in order to identify characteristic safety parameters seems promising for a predictive assessment of road traffic injuries $[7,8]$.

\section{Discussion}

The safety of signaled crossings, roundabouts, junctions at different levels and other road junctions is most often assessed by tracking and statistical analysis of car accident reports. Considering that this approach allows reducing the number and probability of accidents, it, in turn, assumes the availability of stable statistics of car accidents and, therefore, is not applicable for assessing the safety of new projects of road junctions that are just being put into operation. Therefore, a situation arises when, after a certain period of a new road junction functioning due to the high level of road injuries, it requires measures to improve traffic safety. This indicates the need for a more thorough justification of the structural 
parameters of transport facilities during their design and construction, including, the need for preliminary modeling of the consequences of their commissioning, in particular [9-11].

To assess the safety of transport nodes using computer micro modeling and automated accounting for conflict situations one can analyze the existing methods and models proposed by leading experts [12]. The microsimulation model proposed by the authors [13] considers a conflict situation arising on the road, when two vehicles approach each other and, if no action is taken, a collision occurs. The method demonstrates what changes occur at the level of traffic flow (the number of vehicles on one section of the road) and at the level of the vehicle (vehicles choosing different routes). The results show a quantitative relationship between the number of conflicts at priority intersections and the number of passing cars, on the one hand, and the number of accidents observed, on the other hand. When car accidents and conflicts are categorized as accidents, signal connections clearly show the significant differences between the relative number of head-on accidents and conflicts.

Swiss scientists [14] consider simulation models of movement with particular emphasis on understanding traffic jams. It is noted that many models currently used demonstrate similar dynamics of the destruction of traffic flows, i.e. the occurrence of traffic jams. The occurrence of jams in these models implies either permanent jams or spontaneous ones. The strategies discussed to improve traffic flow may vary depending on the road, weather and traffic conditions, depending on the vigilance of the driver and may be different.

Leading experts from Russia [15], who carried out studies related to changes in parameters of the two-component model of the kinetic theory of traffic flows, present the relationship between stopping cars at the same time in the network, a specific travel time and a specific standing time under different driving conditions. The obtained dependences of their research allow predicting changes in traffic conditions taking into account different levels of traffic organization. The paper also discusses the use of information obtained from sounding cars to assess traffic conditions on the road network and proposes an algorithm for modeling the required congestion level of the road network using sounding cars. Currently, there are many tools to model traffic flows. In many countries, experts conduct studies comparing existing systems and software systems for microscopic, macroscopic and mesoscopic modeling. A scientist from the Republic of Poland [16] compared the results of using three selected products (TRANSIMS, SUMO and VISSIM) for microscopic modeling of traffic on a section of an urban road network. The aim of the study was to provide a comparison of the selected microsimulations of the system on a section of the city network. The results revealed some differences. The SUMO model had too low traffic performance compared to the real network one. On the other hand, it was not possible in this work to conduct a comparative assessment of the compliance of the capabilities of two other VISSIM and TRANSIMS models with the real traffic conditions. As the author notes, despite some differences in quantitative indicators, similar effects in the distribution of traffic flow (i.e., the appearance of network bottlenecks and blocking effects) were observed in all three models.

Khaled Shaaban and Inhi Kim [17] compared microscopic motion simulation tools SimTraffic and VISSIM, which are capable of simulating highways with signaled crossings and roundabouts. This study compares the performance of two modeling tools for two-lane and three-lane roundabouts in various scenarios, such as traffic volume, left turn ratio and truck share in traffic. Both modeling tools generally did not show a statistically significant difference. However, in the case of high traffic volumes, VISSIM showed higher average latencies than SimTraffic compared to almost identical results in the case of low traffic volumes.

Authors from the USA [18] applied a two-model approach by combining the CORSIM and VISSIM software packages. This was done to make the analysis results more reliable. 
The results obtained proved the consistency and validity of the modeling tools and provided all participants with confidence in the results of the analysis. The study also demonstrated the value of using a number of performance indicators and sensitivity analysis. More generally, it proved the value of providing as much comparative information as possible before making a design decision. The results were generally consistent, and the end product was a set of clear and well-grounded conclusions. Although the experience gained when using CORSIM and VISSIM was, in some sense, unique to the field under study, it can provide an idea to other transport professionals who are tasked with selecting and applying these simulation models to similar networks.

\section{An analytic survey of microscopic models of road junctions}

An analysis of the work of leading experts in the field of transport planning showed that the VISSIM software product developed by Planung Transport Verkehr AG, Germany is optimal for assessing the safety of traffic intersections. It additionally allowed the user to export vehicle trajectories to the Surrogate Safety Assessment Model software (SSAM) [19]. To assess the capabilities and adequacy of the SSAM methodology, employees of the Federal Highway Administration (FHWA) conducted a theoretical test, analyzing the sensitivity of the hypotheses about the effect of the number of conflicts received from SSAM on the frequency of accidents in real conditions.

The analysis included 83 signaled crossings. Road junctions were modeled on a VISSIM PTV system and evaluated using SSAM software. The results of the analysis of conflict situations at these crossings were compared with actual information about road accidents, which were taken from sources of statistical information.

Conflict data at road junctions based on micro modeling and SSAM were significantly comparable with statistics on accidents at the studied crossings. It is noted that the correlation ratio is more than 0.41 .

Thus, in order to assess the security of the planned road junction using SSAM, it is necessary to develop and verify a simulated micromodel of the future crossing.

To conduct an analytical study, microscopic models of road junctions in the form of a roundabout at one level and a roundabout at different levels were developed. The objective of the study was to obtain comparative data on the predicted safety level of these road junctions before the implementation of measures for their construction.

Figure 1 shows a road junction in the form of a roundabout in the VISSIM PTV environment.

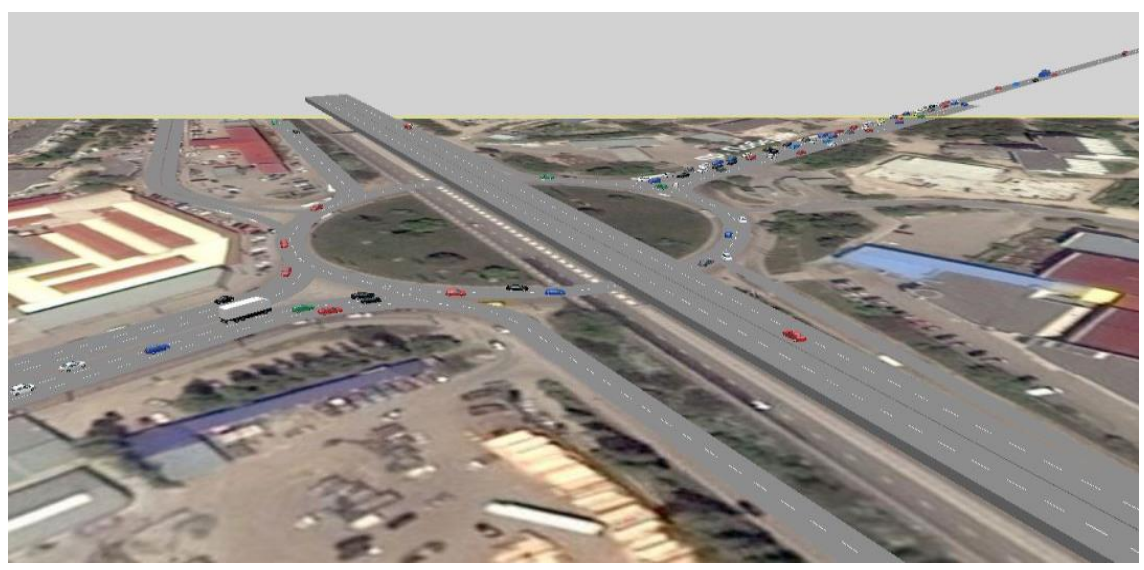

Fig. 1. A road junction in the form of a roundabout in the VISSIM PTV environment. 
Figure 2 shows a road junction in the form of a junction at different levels, made in the PTV VISSIM environment.

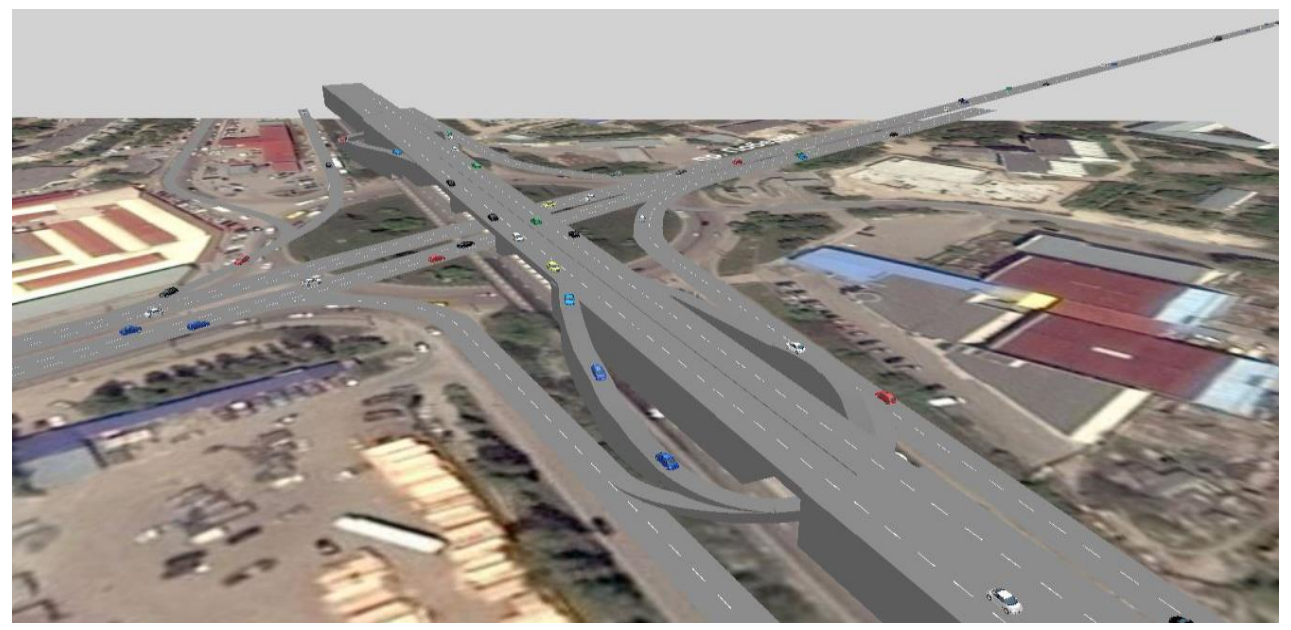

Fig. 2. A road junction in the form of a junction at different levels, made in the PTV VISSIM environment.

The resulting computer models of the micro level were run several times with different starting numbers of vehicles of various types (the composition was set by a software product in an arbitrary form). This was due to the fact that the resulting trajectories of vehicles in microsimulation models were stochastic due to the lack of initial determinism of such models. In this regard, additional simulation runs should be carried out.

At the end of each stage of the simulation, TRJ files corresponding to the trj name extension were obtained. SSAM software was used as a system for post processing the received TRJ files.

Figure 3 shows an example of accident analysis in the form of a heat map indicating the maximum possible number of conflict situations.

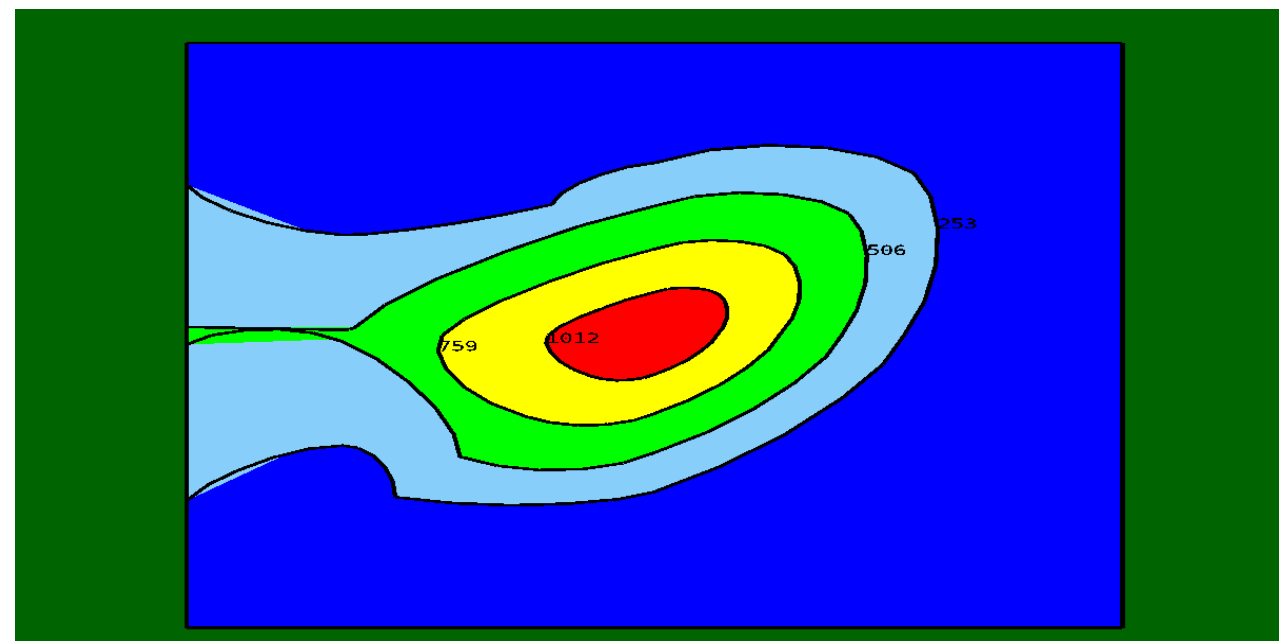

Fig. 3. A heat map of conflicts for a road junction in the form of a roundabout.

SSAM analyzes the interaction between vehicles to identify accidents during the entire simulation period. SSAM also computes several parameters for each event: 
- minimum time before a collision;

- minimum distance to the point of collision;

- initial vehicle braking speed in a simulated accident;

- maximum vehicle braking speed;

- maximum speed of vehicles;

- the difference in the maximum speeds of vehicles, etc.

The output files are:

- a table of all types of accidents;

- a summary of all types of accidents;

- visualization of all accidents in the form of diagrams and heat maps.

Table 2 presents results of the comparative analysis obtained when evaluating the designed road junctions.

Table 2. The comparative analysis obtained when evaluating the designed road junctions.

\begin{tabular}{|c|c|c|c|c|}
\hline$\#$ & $\begin{array}{c}\text { Type of a road } \\
\text { junction }\end{array}$ & $\begin{array}{c}\text { Number of accidents } \\
\text { with } \mathbf{t}_{\mathbf{m i n} 1} \mathbf{(} \mathbf{0 . 5} \\
\text { seconds) }\end{array}$ & $\begin{array}{c}\text { Number of accidents } \\
\text { with } \mathbf{t}_{\mathbf{m i n} 2}(\leq \mathbf{1} \text { seconds) }\end{array}$ & $\begin{array}{c}\text { Number of accidents } \\
\text { with }_{\text {min3 }}(\leq \mathbf{1 . 5} \\
\text { seconds) }\end{array}$ \\
\hline 1 & Roundabout & 654 & 982 & 1,309 \\
\hline 2 & $\begin{array}{c}\text { A road junction at } \\
\text { different levels }\end{array}$ & 256 & 341 & 426 \\
\hline
\end{tabular}

Values $t_{\min 1}, t_{\min 2}, t_{\min 3}$ in table 2 show the time remaining until the moment of collision.

\section{Conclusions}

An analysis of the work of the world's leading transport engineers showed that at the moment there are a large number of software products designed to simulate traffic situations at various levels. The considered computer modeling tools are distinguished by functional capabilities and the degree of complexity of the transport tasks being solved. From the presented analysis it can be concluded that the most suitable tool for assessing the safety of road junctions is the PTV VISSIM software package developed by Planung Transport Verkehr AG, Germany, which also allows to export vehicle trajectories to SSAM software.

In the framework of the analytical survey of the intersection safety, based on the analysis of vehicle trajectories, the parameters of future accidents of the planned road junctions were established. As studies have shown, a road junction at different levels almost triples the safety of intersections in comparison with the considered form of the roundabout. The constraining factor for the construction of multi-level road junction is the significant capital investment that is required to implement such projects. The results of the analysis of the number of accidents of varying complexity are presented in Table 2.

The SSAM software package provides a new way to assess the safety of road junctions using the popular PTV Vision VISSIM microsimulation software. This approach allows not to wait for road accidents at sites, but to evaluate hypothetical structures and alternative layout options for road junctions where it is not possible to apply traditional, statistical models for assessing the probability of the accident. Research in this area is ongoing, and as simulation models and video technologies for recognizing vehicle trajectories improve, this method will be used by specialists when designing integrated traffic management schemes and developing targeted programs to improve road safety. 


\section{References}

1. K. Jamroz, W. Kustra, M. Budzynski, J. Zukowska, Transportation Research Procedia 14, 3905-3914 (2016) DOI: 10.1016/j.trpro.2016.05.479

2. K. Andreev, V. Terentyev, E3S Web of Conferences 135, 02013 (2019) DOI: $10.1051 / \mathrm{e} 3 \operatorname{sconf} / 201913502013$

3. A. Kuraksin, A. Shemyakin, S. Borychev, Transportation Research Procedia, 378-383 (2017) DOI: 10.1016/j.trpro.2017.01.062

4. N. Byshov, A. Simdiankin, I. Usptnsky, Transportation Research Procedia, 107-111 (2017) DOI: 10.1016/j.trpro.2017.01.030

5. Government of the Russian Federation Road Safety Strategy in the Russian Federation for 2018-2024 (2018)

6. https://gibdd.rf/

7. V. Zelikov, G. Denisov, S. Dorokhin, V. Razgonyaeva, N. Zelikova, Studies in Computational Intelligence 826, 1081-1088 (2019) DOI: 10.1007/978-3-030133979111

8. V. Vlasov, A. Novikov, I. Novikov, A. Shevtsova, IOP Conference Series: Materials Science and Engineering Processing Equipment, Mechanical Engineering Processes and Metals Treatment, 042116 (2018) DOI: 10.1088/1757-899X/327/4/042116

9. L. Kushchenko, S. Kushchenko, I. Novikov, A. Novikov, V. Sarbaev, International Journal of Pharmacy and Technology 8(4), 24856-24867 (2016)

10. A. Kuraksin, A. Shemyakin, N. Byshov, Transportation Research Procedia, 386-391 (2018) DOI: 10.1016/j.trpro.2018.12.112

11. A. Levashov, MATEC Web of Conferences electronic edition, 05001 (2018) DOI: 10.1051/matecconf/201821205001

12. V. Zyryanov, V. Kocherga, 13th World Congress on Intelligent Transport Systems and Services 13, ITS: Delivering Transport Excellence (2015) DOI: 10.1088/1757$899 X / 327 / 4 / 042116$

13. A. Dijkstra, Transportation Research Record: Journal of the Transportation Research Board 2147, 105-112 (2010) DOI: 10.3141/2147-13

14. K. Nagel, P. Wagner, R. Woesler, Operations Research 51(5), 681 (2003) DOI: 10.1287/opre.51.5.681.16755

15. V. Zyryanov, V. Kocherga, I. Topilin, Transportation Research Procedia, 746-750 (2017) DOI: 10.1016/j.trpro.2017.01.120

16. M. Maciejewski, Transport Problems 5(4), 27-38 (2010)

17. K. Shaaban, I. Kim, Procedia Computer Science 6, 43-50 (2015) DOI: 10.1016/j.procs.2015.05.016

18. L. Bloomberg, J. Dale, Transportation Research Record 1727, 52-60 (2000) DOI: $10.3141 / 1727-07$

19. https://www.fhwa.dot.gov/publications/research/safety/08049/ 